\title{
Substratos e recipientes para a produção de porta-enxertos de citros irrigados por subcapilaridade
}

\author{
Substrates and containers for the citrus rootstocks' production irrigated by capillarity
}

\author{
Julio Cesar Giuliani ${ }^{{ }^{*}}$ Sandra Rieth ${ }^{\mathrm{I}}$ Wagner Soares ${ }^{\mathrm{I}}$ Gil Lourosa ${ }^{\mathrm{I}}$ Paulo Vitor Dutra de Souza ${ }^{\mathrm{I}}$
}

\section{RESUMO}

O conhecimento do porta-enxerto, do substrato e do recipiente são fundamentais para a definição do período necessário para produzir mudas cítricas de qualidade. O objetivo deste trabalho foi avaliar a emergência de plântulas e o desenvolvimento vegetativo de seis porta-enxertos cítricos, cultivados em dois substratos e mantidos em diferentes recipientes, em sementeira, irrigados por subcapilaridade. Foram testados dois substratos comerciais e a semeadura foi realizada em tubetes com $50 \mathrm{~cm}^{3}$, tubetes com $120 \mathrm{~cm}^{3}$ e bandejas de isopor contendo 72 células com volume de $120 \mathrm{~cm}^{3}$. Os seis porta-enxertos cítricos avaliados foram: Trifoliata [Poncirus trifoliata [L.] Raf.]; Flying Dragon [Poncirus trifoliata (L.) Raf. var. monstrosa]; limoeiro Volkameriano (Citrus volkameriana Pasq.), citrangeiro Fepagro C37 [P. trifoliata $x$ Citrus sinensis [L.] Osbeck.], tangerineira Sunki (C. sunki hort. ex Tan.) e citrumeleiro Swingle (P. trifoliata $\times$ C. paradisi). Avaliou-se emergência, altura e diâmetro das plantas ao longo do cultivo em casa de vegetação. Em laboratório, avaliou-se massa fresca e seca da parte aérea e raiz, número de folhas, área foliar por folha e área foliar por planta. Nas avaliações de emergência de plântulas, a tangerineira Sunki, o limoeiro Volkameriano e o citrumeleiro Swingle apresentaram maiores taxas em relação ao Trifoliata, ao citrangeiro Fepagro $C$ 37 e ao Flying Dragon. Ao empregar-se o sistema de irrigação por subcapilaridade, o substrato comercial 1 é recomendado para todos recipientes. O substrato comercial 2 somente deve ser empregado em bandejas alveoladas de $120 \mathrm{~cm}^{3}$.

Palavras-chave: propagação, ambiente protegido, desenvolvimento vegetativo, citricultura.

\section{ABSTRACT}

In the production of citrus seedling, the knowledge of rootstock substrate and container is essential to define the entire substantial period to produce quality seedling. The objective of this research was to evaluate seedling emergence and vegetative development of six citrus rootstocks grown on two substrates and kept in different containers at the stage of sowing irrigated by capillarity. Two commercial substrates were tested and seeding was performed in three containers: stiff plastic tubes with $50 \mathrm{~cm}^{3}$, stiff plastic tubes with $120 \mathrm{~cm}^{3}$ and polystyrene trays containing 72 cells with a volume of $120 \mathrm{~cm}^{3}$. The six rootstocks citrus evaluated were: Trifoliata [Poncirus trifoliata [L.] Raf.]; Flying Dragon [Poncirus trifoliata (L.) Raf. var. monstrosa]; Volkameriano lemon (Citrus volkameriana Pasq.), Fepagro C37 citrange [P. trifoliata $\times$ Citrus sinensis [L.] Osbeck.], Sunki tangerine (C. sunki hort. ex Tan.) and Swingle citrumelo (P. trifoliata $x$ C. paradisi). The emergence, height and diameter of plants in the greenhouse were evaluated. Fresh weight, root and shoot dry weight, leaf number, leaf area per plant and leaf area per leaf were evaluated in the laboratory. In the evaluations of emergence of seedlings, the Sunki tangerine, Volkameriano lemon and Swingle citrumelo had higher rates compared to Trifoliata, Fepagro C37 citrange and Flying Dragon. When the system in a floating irrigation system, commercial substrate 1 is recommended for all containers. The commercial substrate 2 should be only used in alveolate trays of $120 \mathrm{~cm}^{3}$.

Key words: propagation, greenhouse, vegetative growth, citrus.

\section{INTRODUÇÃO}

A formação da muda em menor tempo possível, com o máximo vigor e custo menor, depende inicialmente das características do substrato utilizado e também do volume de recipiente, definido pelo seu tamanho e forma, quando deverá ocorrer o desenvolvimento do sistema radicial, além de outros fatores (OLIVEIRA et al., 2006).

Mesmo havendo vários estudos com substratos, muitos materiais têm sido utilizados comercialmente sem que uma caracterização prévia

'Departamento de Horticultura e Silvicultura, Faculdade de Agronomia, Universidade Federal do Rio Grande do Sul (UFRGS), Av. Bento Gonçalves 7712, CP 15100, 91501-970, Porto Alegre, RS, Brasil. E-mail: juliocgiuliani@yahoo.com.br. *Autor para correspondência. 
adequada tenha sido feita, levando à perda de credibilidade pela empresa fabricante do substrato e a prejuízos financeiros para o produtor. Outro fator importante é a definição do tamanho, altura e diâmetro do recipiente, que influenciam diversas características da muda e podem impactar no percentual de sobrevivência no campo e a produtividade da cultura (LIMA et al., 2006).

No cultivo de porta-enxertos cítricos, o molhamento da parte aérea da planta pode facilitar o estabelecimento de doenças fúngicas e bacterianas que são disseminadas pela água (SCHÄFER, 2004; TEIXEIRA, 2008). O sistema de irrigação por subcapilaridade vem sendo utilizado na produção de porta-enxertos de citros, mostrando-se eficiente na fase de sementeira, permitindo ganhos em altura de plantas de até $64 \%$ e de $66,7 \%$ para área foliar, obtendo melhorias no aspecto fitossanitário das plantas e permitindo a aplicação de fertilizantes via água de irrigação (SCHÄFER, 2004; TEIXEIRA, 2008).

Na produção de mudas de qualidade, devese atentar para aspectos fundamentais ligados à garantia genética, aos métodos de propagação, aos sistemas de produção e à legislação vigente (SOUZA \& SCHÄFER, 2009; SOUZA et al., 2010). Dessa forma, é necessário que os porta-enxertos propiciem condições para que a muda possa se desenvolver com êxito. Estes aspectos interferem no desenvolvimento da planta, podendo afetar mais de 20 características hortícolas e fitossanitárias da variedade copa, entre elas: vigor, tolerância a doenças e temperatura baixas e qualidade dos frutos (SCHÄFER et al., 2004).

Dentre as fases de desenvolvimento da muda cítrica, a produção do porta-enxerto é responsável pela maior demanda de tempo. Um dos fatores responsáveis por essa demora é o tempo de germinação, assim como a desuniformidade no número de dias para ocorrência da germinação dos diferentes porta-enxertos de citros na fase de sementeira (SOUSA et al., 2002). O conhecimento desta fase, que é variável por cultivar, é importante para definição do período necessário para a produção da muda.

O presente trabalho teve como objetivo avaliar a emergência de plântulas e o desenvolvimento vegetativo de seis porta-enxertos cítricos, cultivados em dois substratos e mantidos em diferentes recipientes na fase de sementeira.

\section{MATERIAL E MÉTODOS}

O trabalho foi desenvolvido no período de junho a dezembro de 2010, na Estação Experimental Agronômica da Universidade Federal do Rio Grande do Sul (EEA/UFRGS), situada na rodovia BR 290 (Km 146), em Eldorado do Sul, RS, e também no laboratório do Departamento de Horticultura e Silvicultura (DHS), localizado no Campus da Faculdade de Agronomia na Universidade Federal do Rio Grande do Sul (UFRGS), em Porto Alegre.

Foram utilizadas sementes coletadas de frutos maduros de plantas cultivadas na coleção de citros da EEA/UFRGS (latitude $30^{\circ} 05^{\prime}$ 52" S e longitude $51^{\circ} 39^{\prime} 08^{\prime}$ ' W) e plantas do pomar da Empresa Panoramas Citrus, situada no município de Butiá - RS (latitude $30^{\circ} 07^{\prime} 12^{\prime \prime}$ S, longitude $51^{\circ}$ 57' 45” W). A metodologia adotada para a extração das sementes é descrita por KOLLER (1994). Após a extração, as sementes foram secas à sombra em temperatura ambiente por 48 horas. Após, foram polvilhadas com fungicida Captan até a completa cobertura do tegumento, acondicionadas em sacos plásticos e mantidas em geladeira $\left(4\right.$ a $\left.6^{\circ} \mathrm{C}\right)$ até o momento da semeadura.

Na semeadura, colocaram-se duas sementes por alvéolo à profundidade de $1,5 \mathrm{~cm}$ da superfície do substrato. Após a emergência das plântulas, fez-se um desbaste, deixando apenas uma planta por tubete ou célula, mantendo-se aquela com maior vigor. Este desbaste foi realizado quando as plântulas estavam com aproximadamente 4 a $5 \mathrm{~cm}$ de altura.

Avaliaram-se dois diferentes substratos comerciais: a) comercial 1 - composto basicamente por turfa, casca de arroz carbonizada, vermiculita e adubação química; b) comercial 2 - caracterizado pela presença de turfa, casca de arroz queimada e casca de arroz carbonizada, além de um composto orgânico a base de cama de aviário e engaço de uva.

Também foram avaliados três recipientes: a) recipiente 1 - bandejas de isopor contendo 72 células com volume útil de $120 \mathrm{~cm}^{3}$ em cada célula; b) recipiente 2 - tubetes cônicos de polietileno preto com volume útil de $50 \mathrm{~cm}^{3}$; c) recipiente 3 - tubetes cônicos de polietileno preto com volume útil de $120 \mathrm{~cm}^{3}$. Os três recipientes eram vazados na parte basal, sendo que os tubetes foram fixados em bancadas metálicas a um metro da superfície.

Os seis porta-enxertos cítricos cultivados foram: o Trifoliata (Poncirus trifoliata Raf.); o Flying Dragon (P. trifoliata var. monstrosa); o citrangeiro Fepagro C 37 (P. trifoliata x Citrus sinensis (L.) Osbeck); o limoeiro Volkameriano (C. volkameriana Pasq.); a tangerineira Sunki (C. sunki Hort. ex Tan.); e o citrumeleiro Swingle (P. trifoliata x $\boldsymbol{C}$. paradisi Macf.).

As irrigações foram realizadas por um sistema de subirrigação por capilaridade, seguindo metodologia descrita por SCHÄFER (2004), o qual se 
constituía da imersão de dois terços basais dos tubetes em água, dispostos em suportes sob tanque metálico. O sistema era acionado por um timer eletrônico por uma hora pela manhã e uma hora no final do dia.

Em casa de vegetação, foram realizadas as seguintes avaliações: percentual de recipientes dos quais emergiu ao menos uma plântula; velocidade de emergência, determinada mediante contagens constantes do número de sementes emergidas; comprimento da parte aérea, medida com uma régua graduada da superfície do recipiente até o meristema apical, em cm; diâmetro do colo, medido há um centímetro da superfície do recipiente com um paquímetro digital, em mm.

Em laboratório, foram avaliados: massa fresca da raiz e parte aérea, em gramas; massa seca da raiz e parte aérea, em gramas, obtidas pela secagem à estufa, com temperatura de $65^{\circ} \mathrm{C}$, até peso constante; área foliar por planta e área foliar por folha, em $\mathrm{cm}^{2}$, medidas através da passagem das folhas por um medidor de área foliar de marca LI-Cor, modelo LI - 3100.

O experimento foi conduzido em esquema fatorial 2x3x6 (substrato, recipiente e porta-enxerto), em delineamento experimental de blocos casualizados com três repetições e tratamentos dispostos em parcelas subsubdivididas, sendo cada subparcela constituída por 12 plantas com três repetições, sendo testados dois substratos (parcela principal), três tipos de recipientes (subparcela) e seis diferentes porta-enxertos (subsubparcela). A análise estatística constou da análise de variância dos dados (ANOVA) transformados em raiz quadrada de $(\mathrm{x}+1)$, e as diferenças entre as médias foram realizadas pelo teste de Tukey $(\mathrm{P}<0,05)$. As variáveis velocidade de emergência e altura das plantas no decorrer do experimento foram submetidas à análise de regressão polinomial.

\section{RESULTADOS E DISCUSSÃO}

Aos 91 dias após a semeadura (DAS), observou-se interação significativa entre os fatores substrato e porta-enxerto e entre substrato e recipiente, para o percentual de emergência de plântulas. A figura 1 apresenta a velocidade de emergência dos porta-enxertos ao longo de nove avaliações, em que estão representados os dois substratos comerciais (nas colunas) e os três recipientes utilizados (nas linhas).

$O$ uso do substrato comercial 1 na semeadura mostrou-se eficiente com a utilização dos três recipientes (Figuras 1A, 1C e 1E), não apresentando diferença significativa na emergência final e proporcionando alto percentual de emergência com 20 dias de antecipação, comparado ao cultivo com o substrato comercial 2 (Figuras 1B, 1D e 1F).

A semeadura em tubetes de $50 \mathrm{~cm}^{3}$ e $120 \mathrm{~cm}^{3}$ com uso do substrato comercial 2, prejudicou significativamente a emergência final dos portaenxertos (Figuras 1D, 1F), não superando os 50\% de emergência no tubete menor e os $40 \%$, no maior. Quando semeados em bandejas, independentemente do substrato, e nos tubetes de $50 \mathrm{~cm}^{3}$ e $120 \mathrm{~cm}^{3} \mathrm{com}$ o substrato comercial 1, as velocidades de emergência superaram os 50\%, chegando aos $90 \%$ de emergência em algumas variedades de porta-enxertos.

Utilizando o substrato comercial 2 em bandejas (Figura 1B), verificou-se que os portaenxertos apresentaram incrementos diferenciados na velocidade de emergência, sendo que os porta-enxertos Sunki, Volkameriano e Fepagro C 37 apresentaram resposta quadrática e maior percentual de emergência aos 91 DAS. Ao ser cultivada nos três recipientes com o substrato comercial 1 (Figuras 1A, 1C e 1E), a tangerineira Sunki apresentou maior velocidade de emergência em relação aos outros porta-enxertos, inclusive destacando-se juntamente com o Trifoliata, Volkameriano e o Swingle, com maior porcentagem final de emergência.

O substrato Comercial 2 apresentou menor eficiência na germinação dos porta-enxertos em tubetes de 50 e $120 \mathrm{~cm}^{3}$ (Figuras 1D e 1F), havendo baixa porcentagem de emergência de plântulas, comparado com os outros tratamentos, acarretando em diminuição e atraso na emergência.

Verificou-se, nos tubetes $\left(50 \mathrm{~cm}^{3}\right.$ e $\left.120 \mathrm{~cm}^{3}\right)$ preenchidos com substrato comercial 2, que, em virtude de receberem água por capilaridade e serem mais altos que as bandejas, a camada superior de substrato (onde estavam as sementes) permanecia mais seca, provavelmente deixando parte das sementes desidratadas e impedindo sua germinação.

Nas avaliações finais de altura, diâmetro, massa seca e área foliar (Tabelas 1 e 2), não houve interação significativa entre substrato, recipiente e porta-enxerto. Verificou-se diferença significativa entre os porta-enxertos e os recipientes, não havendo efeito dos substratos nas avaliações de vigor das plantas.

O Trifoliata e o citrangeiro Fepagro C37 foram superiores em altura, não diferindo estatisticamente do Flying Dragon e do citrumeleiro Swingle; a tangerineira Sunki e o limoeiro Volkameriano apresentaram menores alturas (Tabela 1). TEIXEIRA (2008), em trabalho comparando dois recipientes na fase de sementeira, verificaram comportamento 


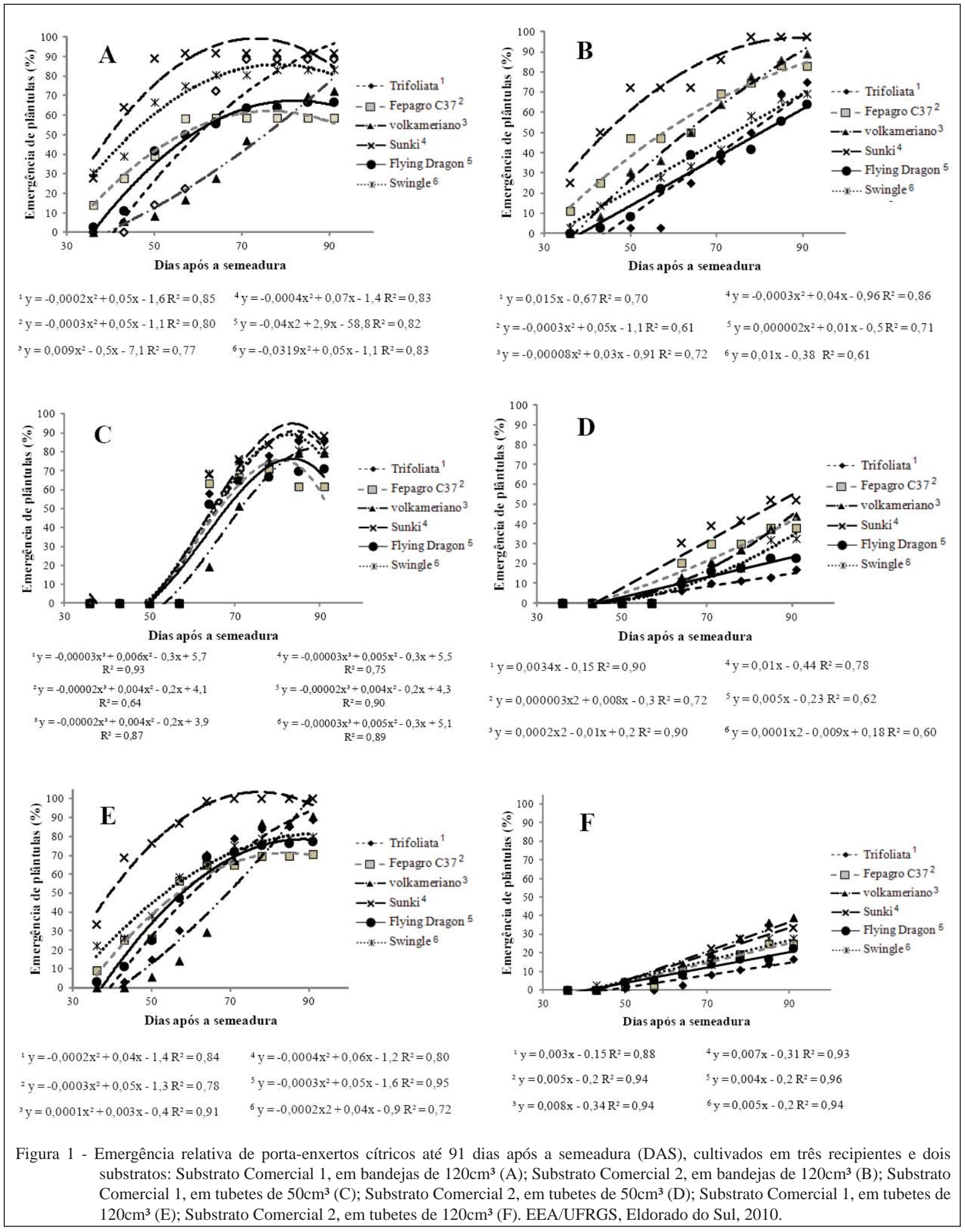

em altura semelhante do Trifoliata e o Fepagro C 37 e significativamente maior que a tangerineira Sunki, confirmando os resultados do presente estudo.
SCHÄFER (2004) também encontrou resultados semelhantes em altura final na fase de sementeira dos porta-enxertos Trifoliata e Fepagro C 37.

Ciência Rural, v.44, n.3, mar, 2014. 
Tabela 1 - Altura final, diâmetro, massa seca (MS) da raiz, parte aérea e massa seca total de porta-enxertos cítricos, cultivados em diferentes recipientes e substratos em casa de vegetação, na fase de sementeira. EEA/UFRGS, Eldorado do Sul, 2010.

\begin{tabular}{|c|c|c|c|c|c|c|c|c|c|c|c|}
\hline \multirow[t]{3}{*}{ Tratamento } & \multirow[b]{3}{*}{ Bandeja } & \multirow{2}{*}{\multicolumn{2}{|c|}{$\begin{array}{l}\text {----- Altura ----- } \\
\text {------ (cm) ------ }\end{array}$}} & \multirow{2}{*}{\multicolumn{2}{|c|}{$\begin{array}{l}\text {---- Diâmetro ---- } \\
\text {--- -- (mm) ---- - }\end{array}$}} & \multirow{2}{*}{\multicolumn{2}{|c|}{------- raiz ------- }} & \multicolumn{4}{|c|}{ 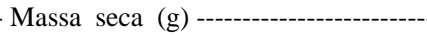 } \\
\hline & & & & & & & & ---- p. A & ea ----- & ------- tc & l ------ \\
\hline & & 11,67 & $a b^{1}$ & 1,96 & $\mathrm{ab}$ & 0,69 & $\mathrm{ab}$ & 1,66 & $\mathrm{Ab}$ & 2,31 & $\mathrm{ab}$ \\
\hline \multirow[t]{2}{*}{ Recipientes } & Tubete $50 \mathrm{~cm}^{3}$ & 13,44 & a & 2,24 & a & 0,82 & $\mathrm{a}$ & 1,99 & A & 2,80 & $\mathrm{a}$ \\
\hline & Tubete $120 \mathrm{~cm}^{3}$ & 6,08 & $\mathrm{~b}$ & 1,19 & $\mathrm{~b}$ & 0,42 & $\mathrm{~b}$ & 0,88 & B & 1,25 & $\mathrm{~b}$ \\
\hline \multicolumn{2}{|l|}{$\mathrm{CV}(\%)$} & \multicolumn{2}{|l|}{44,2} & \multicolumn{2}{|l|}{27,1} & \multicolumn{2}{|l|}{17,07} & \multicolumn{2}{|l|}{26,7} & \multicolumn{2}{|l|}{31,0} \\
\hline \multirow{6}{*}{ Porta-enxertos } & Trifoliata & 12,32 & a & 1,79 & a & 0,66 & $a b$ & 1,28 & $\mathrm{Bc}$ & 1,92 & bc \\
\hline & Fepagro C 37 & 12,18 & a & 1,99 & $\mathrm{a}$ & 0,72 & $\mathrm{ab}$ & 1,89 & A & 2,61 & a \\
\hline & Volkameriano & 8,93 & bc & 1,96 & a & 0,82 & $\mathrm{a}$ & 1,86 & A & 2,65 & a \\
\hline & Sunki & 6,95 & c & 1,34 & $\mathrm{~b}$ & 0,37 & C & 1,13 & $\mathrm{C}$ & 1,50 & c \\
\hline & Flying Dragon & 10,09 & $\mathrm{ab}$ & 1,72 & $\mathrm{ab}$ & 0,54 & bc & 1,07 & $\mathrm{C}$ & 1,59 & c \\
\hline & Swingle & 11,04 & $\mathrm{ab}$ & 1,86 & a & 0,74 & $\mathrm{ab}$ & 1,68 & $\mathrm{ab}$ & 2,39 & $\mathrm{ab}$ \\
\hline CV (\%) & & \multicolumn{2}{|l|}{10,5} & \multicolumn{2}{|l|}{7} & \multicolumn{2}{|l|}{6,3} & \multicolumn{2}{|l|}{9,4} & \multicolumn{2}{|l|}{10,5} \\
\hline \multirow{2}{*}{ Substratos } & Comercial 1 & \multicolumn{2}{|l|}{$12,3^{\mathrm{ns}}$} & \multicolumn{2}{|l|}{$2,10^{\mathrm{ns}}$} & \multicolumn{2}{|l|}{$0,69^{\mathrm{ns}}$} & \multicolumn{2}{|l|}{$1,56^{\mathrm{ns}}$} & \multicolumn{2}{|l|}{$2,42^{\mathrm{ns}}$} \\
\hline & Comercial 2 & \multicolumn{2}{|l|}{9,90} & \multicolumn{2}{|l|}{1,63} & \multicolumn{2}{|l|}{0,44} & \multicolumn{2}{|l|}{1,25} & \multicolumn{2}{|l|}{1,76} \\
\hline \multicolumn{2}{|l|}{ CV (\%) } & \multicolumn{2}{|l|}{53,3} & \multicolumn{2}{|l|}{42,5} & \multicolumn{2}{|l|}{21,6} & \multicolumn{2}{|l|}{37,1} & 43,9 & \\
\hline
\end{tabular}

${ }^{1}$ Médias seguidas por letras distintas, na coluna, diferem entre si, pelo teste de Tukey $(\mathrm{P}<0,05)$; ns = não significativo.

A diferença entre os porta-enxertos é comum de ser encontrada, podendo-se atribuí-la às diferentes características genéticas (SCHÄFER, 2004), que influenciam na capacidade de uso de luz e $\mathrm{CO}_{2}$, afetando a absorção, o transporte e a interação dos nutrientes dentro da planta (FOCHESATO, 2005).

A tangerineira Sunki apresentou menores desempenhos em altura, diâmetro e massa seca de raiz e parte aérea (Tabela 1). Alguns autores apresentaram resultados semelhantes, quando esta tangerineira apresentou menores incrementos no vigor inicial comparando a outros porta-enxertos na produção de mudas (DECARLOS et al., 2002; TEIXEIRA, 2008; TEIXEIRA et al., 2010).

Na quantidade de massa seca da raiz, o limoeiro Volkameriano foi superior, não diferindo do Trifoliata, do Fepagro C 37 e do citrumeleiro Swingle (Tabela 1). Analisando-se a massa seca da parte aérea, os porta-enxertos Volkameriano e Fepagro C 37 apresentaram maiores valores, não diferindo do Swingle. Já o Trifoliata, o Flying Dragon e a tangerineira Sunki foram inferiores. Em experimento realizado por TEIXEIRA et al. (2010), no qual foi avaliado o desenvolvimento vegetativo de porta- enxertos produzidos em diferentes doses de adubo, também se verificou superioridade do citrumeleiro Swingle em relação ao Sunki e o Trifoliata nas avaliações de massa seca da parte aérea.

SCHÄFER et al. (2004), testando diferentes substratos cultivados em tubetes de $120 \mathrm{~cm}^{3}$, verificaram que o porta-enxerto Fepagro C 37 apresentou os maiores índices de diâmetro e massa seca aos 120 dias após a semeadura, seguido pelo Trifoliata e pelo Fepagro C 13 e, por último, pelo limoeiro Cravo.

A menor massa seca apresentada pelo Trifoliata e o Flying Dragon pode ser explicada pelo menor tamanho e área de suas folhas. Também apresentam caráter caducifólio, que, em resposta às temperaturas amenas, reduzem drasticamente sua atividade metabólica e vigor (LEITE JUNIOR, 1992). FOCHESATO et al. (2007), avaliando o crescimento vegetativo de três porta-enxertos cítricos em diferentes substratos, também encontraram menor acúmulo de massa seca do Trifoliata. Avaliando o desenvolvimento inicial de seis portaenxertos cítricos, FRANCO et al. (2007) observaram superioridade em massa seca dos porta-enxertos Volkameriano e Swingle comparando ao Trifoliata, confirmando os resultados do presente estudo. 
Tabela 2 - Área foliar por planta e área foliar por folha de portaenxertos cítricos, cultivados em diferentes recipientes e substratos em casa de vegetação, na fase de sementeira. EEA/UFRGS, Eldorado do Sul, 2010.

\begin{tabular}{llllll}
\hline Tratamento & & \multicolumn{2}{c}{$\begin{array}{c}\text { Área foliar } \\
\left(\mathrm{cm}^{2} \text { planta }^{-1}\right)\end{array}$} & $\begin{array}{c}\text { Área foliar } \\
\left(\mathrm{cm}^{2} \text { folha }\right.\end{array}$ \\
\hline \multirow{2}{*}{ Recipientes }
\end{tabular}

${ }^{1}$ Médias seguidas por letras distintas, na coluna, diferem entre si, pelo teste de Tukey $(\mathrm{P}<0,05)$; ns = não significativo.

A superioridade do limoeiro Volkameriano comparado à tangerineira Sunki foi verificada também por DECARLOS et al. (2002), em que este limoeiro apresentou, na avaliação final da fase de sementeira, maiores valores de altura, diâmetro do colo, área foliar por planta e massa seca.

Verificou-se que, para todas as avaliações de vigor (Tabelas 1 e 2), os recipientes proporcionaram comportamentos similares. Os tubetes de $50 \mathrm{~cm}^{3}$ proporcionaram os melhores resultados, não diferindo estatisticamente das bandejas. Já as plantas cultivadas nos tubetes de $120 \mathrm{~cm}^{3}$ mostraram-se inferiores às demais. Nas avaliações de vigor, ao final da fase de sementeira (Tabelas 1 e 2), não houve influência do fator substrato.

Tais resultados aqui relatados corroboram os obtidos por TEIXEIRA (2008), avaliando o desenvolvimento vegetativo de porta-enxertos cítricos, que verificaram superioridade no cultivo em bandejas, comparado aos tubetes de $120 \mathrm{~cm}^{3}$ na utilização do sistema de irrigação por subcapilaridade na fase de sementeira. Para esses autores, a diferença na altura dos recipientes irrigados sob sistema de irrigação por subcapilaridade influenciaram os resultados.
Na análise de área foliar por planta e área foliar por folha (Tabela 2), o limoeiro Volkameriano obteve maiores valores; já os porta-enxertos Trifoliata e Flying Dragon mostraram-se inferiores; os demais apresentaram valores intermediários. Essa diferença nas áreas foliares deve-se às características morfológicas de cada porta-enxerto, sendo que o $\boldsymbol{P}$. trifoliata, seus híbridos (Fepagro C 37, e citrumeleiro Swingle) e sua variação botânica (Flying Dragon) apresentam folhas trifolioladas, que possuem menor área foliar que os outros porta-enxertos (SOUZA \& SCHÄFER, 2009). A tangerineira Sunki, por ter folhas pequenas, apresentou valores de área foliar semelhantes às folhas trifolioladas dos porta-enxertos Fepagro C 37 e Swingle.

SCHÄFER (2004), aos 120DAS, encontrou diferença no desenvolvimento vegetativo dos porta-enxertos Fepagro C 37 e Trifoliata. Este último apresentou baixo índice de área foliar, pelas características intrínsecas da própria espécie, pois é normal este porta-enxerto apresentar folhas menores, quando comparado a outros porta-enxertos cítricos (SCHÄFER, 2004).

\section{CONCLUSÃO}

A tangerineira Sunki, o limoeiro Volkameriano e o citrumeleiro Swingle apresentam maiores taxas de emergência em relação ao Trifoliata, ao citrangeiro Fepagro C 37 e ao Flying Dragon. Na fase de sementeira, não há necessidade de uso de tubetes de $120 \mathrm{~cm}^{3}$ para a produção de porta-enxertos de citros, sendo suficientes bandejas alveoladas de $120 \mathrm{~cm}^{3}$ ou tubetes de $50 \mathrm{~cm}^{3}$.

Ao empregar-se sistema de irrigação por subcapilaridade, o substrato comercial 1 é recomendado para bandejas alveoladas de $120 \mathrm{~cm}^{3}$ e para tubetes de $50 \mathrm{~cm}^{3}$ e $120 \mathrm{~cm}^{3}$. O substrato comercial 2 somente deve ser empregado em bandejas alveoladas de $120 \mathrm{~cm}^{3}$.

\section{REFERÊNCIAS}

DECARLOS, A.N. et al. Crescimento de porta-enxertos de citros em tubetes influenciados por doses de N. Revista Brasileira de Fruticultura, Jaboticabal, v.24, n.1, p.199-203, 2002. Disponível em: <http://www.scielo.br/scielo.php?pid=S010029452002000100043\&script $=$ sci_arttext $>$. Acesso em: 18 nov. 2011. doi: 10.1590/S0100-29452002000100043.

FOCHESATO, M. L. Substratos e porta-enxertos na produção de mudas cítricas em ambiente protegido. 2005. 102 f. Dissertação (Mestrado) - Programa de Pós-Graduação em Fitotecnia, Faculdade de Agronomia, Universidade Federal do Rio Grande do Sul, Porto Alegre, 2005. 
FOCHESATO, M.L. et al. Crescimento vegetativo de portaenxertos de citros produzidos em substratos comerciais. Ciência Rural, Santa Maria, v.37, n.4, p.970-975, 2007. Disponível em: <http://www.scielo.br/scielo.php?pid=S010384782007000400008\&script=sci_arttext $>$. Acesso em: 18 out. 2011. doi: 10.1590/S0103-84782007000400008.

FRANCO, D. et al. Avaliação de substratos no desenvolvimento inicial de seis porta-enxertos de citros. Laranja, Cordeirópolis, v.28, n.1-2, p.61-70, 2007.

LEITE JUNIOR, R.P. Cultivares de copa e porta-enxertos. In IAPAR. A citricultura no Paraná. Londrina, 1992. p.91-116. (Circular, 72).

LIMA, R.S. et al. Volume de recipientes e composição de substratos para produção de mudas de mamoneira. Ciência e Agrotecnologia, Lavras, v.30, n.3, p.480-486, 2006. Disponível em: <http://www.scielo.br/scielo.php?pid=S141370542006000300014\&script=sci_abstract \&tlng=pt $>$. Acesso em: 16 set. 2011. doi: 10.1590/S1413-70542006000300014.

OLIVEIRA, R.P. de et al. Escarificação química da semente para favorecer a emergência e o crescimento do porta-enxerto Trifoliata. Pesquisa Agropecuária Brasileira, Brasília, v.41, n.9, p.1429-1433, 2006. Disponível em: <http://www.scielo. br/scielo.php?pid=S0100-204X2006000900012\&script $=$ sci arttext>. Acesso em: 20 jan. 2012. doi:10.1590/S0100204X2006000900012.

SCHÄFER, G. Produção de porta-enxertos cítricos em recipientes e ambiente protegido no Rio Grande do Sul.
2004. 129f. Tese (Doutorado em Fitotecnia) - Programa de Pósgraduação em Fitotecnia, Faculdade de Agronomia, Universidade Federal do Rio Grande do Sul, Porto Alegre, RS.

SOUSA, H.U. et al. Efeito do ácido giberélico sobre a germinação de sementes de porta-enxertos cítricos. Revista Brasileira de Fruticultura, Jaboticabal, v.24, n.2, p.496-499, 2002. Disponível em: <http://www.scielo.br/scielo.php?pid=S010029452002000200043\&script=sci_abstract\&tlng=pt>. Acesso em: 16 mai. 2012. doi: 10.1590/S0100-29452002000200043.

SOUZA, P.V.D.; SCHÄFER, G. Produção de mudas de tangerineiras. In: KOLLER, O.C. Cultura de tangerineiras: Tecnologia de produção, pós-colheita e industrialização. Porto Alegre: Riegel, 2009. p.63-89.

SOUZA, E.L. da S. et al. Porta-enxertos para citros no Rio Grande do Sul. - Indicações técnicas para a citricultura no Rio Grande do Sul. Porto Alegre: FEPAGRO, 2010. 126p.

TEIXEIRA, P. T. L. Tecnologias para a produção de portaenxertos cítricos em ambiente protegido. 2008. 131 f. Tese (Doutorado) - Programa de Pós-Graduação em Fitotecnia, Faculdade de Agronomia, Universidade Federal do Rio Grande do Sul, Porto Alegre, 2008.

TEIXEIRA, P.T.L. et al. Desenvolvimento vegetativo e acúmulo de massa seca com a adubação de porta-enxertos cítricos cultivados em tubetes. Ciência Rural, Santa Maria, v.40, n.12, p.2603-2607, 2010. Disponível em: <http://www.scielo.br/scielo. php?pid=S0103-84782010001200027\&script $=$ sci_arttext $>$. Acesso em: 25 jan. 2012 doi: 10.1590/S0103-84782010005000198. 